\title{
BURDEN OF RESPIRATORY DISEASE AMONG PAEDIATRIC PATIENTS INFECTED WITH HIV
}

\begin{abstract}
The effects of paediatric HIV on the respiratory system are seen daily in paediatric wards. The nature of respiratory disease and the needs of HIV-positive patients have changed subsequent to the introduction of anti-retrovirals to South Africa in 2004.

One hundred and twenty five children admitted to the paediatric wards under the age of seven years were recruited for this study. The purpose of this study was to understand the disease profile of children with HIV/AIDS, their health status, presenting respiratory conditions, and need for chest physiotherapy.
\end{abstract}

The most common respiratory conditions included bacterial pneumo-

\begin{tabular}{c} 
Da Cunha NCP, \\
MSc Paediatric Physiotherapy'; \\
Potterton JL, PhD Physiotherapy'; \\
Humphries CRM, \\
MSc Paediatric Physiotherapy' \\
1 University of the Witwatersrand, \\
Department of Physiotherapy. \\
\hline
\end{tabular}
nia (66.4\%), tuberculosis (48\%) and pneumocystis jirovecii pneumonia (23.2\%) (n=125). Two thirds of the children (68.8\%) presented with a high burden of disease. Forty percent (40.8\%) of the children were taking anti-retrovirals with an average length of use of 9.81 months $( \pm S D=11.61)$. Analysis of immune status revealed a mean $C D 4$ percentage of $17.33 \%( \pm S D=10.96), C D 4$ absolute $631.36 \mathrm{cell} / \mathrm{mm} 3( \pm S D=610.36)$ and viral load 2.6 million copies $/ \mathrm{ml}( \pm S D=9.08$ million copies $/ \mathrm{ml})$.

This study highlights the characteristics and prevalence of respiratory disease burden among children with HIV in a South African setting in a post highly active antiretroviral era.

KEY WORDS: RESPIRATORY DISEASE; CHILDREN; HIV; ANTIRETROVIRAL THERAPY; PHYSIOTHERAPY.

\section{INTRODUCTION}

Sub-Saharan Africa remains the region of the world most heavily affected by HIV. In 2011, sub-Saharan Africa accounted for $69 \%$ of HIV infections worldwide. Mother-to-child transmission continues to account for a substantial portion of new HIV infections in many African countries. In 2011, more than $90 \%$ of children were newly infected in sub-Saharan Africa (UNAIDS, 2012). Respiratory disease remains a major cause of morbidity and mortality

\section{Correspondence Author:}

Mrs CRM Humphries

Physiotherapy Department,

Khanya Block

University of the Witwatersrand

7 York Road

Parktown 2193

South Africa

Email: Carolyn.humphries@wits.ac.za amongst HIV-infected children (Zar, 2008). Zar and Mulholland reported in 2003 that of more than one and a half million HIV infected children, $90 \%$ will develop a respiratory illness sometime in the course of their HIV condition.

The management of HIV has made progress in South Africa and therefore, the incidence of acute and opportunistic respiratory infections has declined while HIV-associated chronic lung disease has increasingly emerged (Zar, 2008). The incidence of acute pneumonia is much higher in HIV infected than uninfected children (Madhi et al, 2000) and chronic lung diseases are much more common owing to a wider range of pulmonary diseases (Graham, 2005). Pneumocystis jirovecii pneumonia (PJP) is by far the most common opportunistic infection and serves as an HIV marker and many other studies have shown that PJP, cytomegalovirus (CMV), mycobacterium avium complex (MAC) and pulmonary tuberculosis (PTB) are among the most common opportunistic infections (Parker et al, 1998). In children with HIV infection, lymphoid interstitial pneumonitis (LIP) has been designated as an AIDS-defining illness by the US Centres for Disease Control and Prevention (1994). Pulmonary infection may develop chronicity. This is illustrated by the significant occurrence of bronchiectasis in children with AIDS, particularly in children developing LIP, recurrent pneumonia and unresolved pneumonia (Sheikh et al, 1997).

There are many other factors which may contribute towards the prevalence of acute and chronic respiratory conditions including age and health status (Graham, 2007). Survival rates have increased with improved treatment strategies (Graham, 2007). The CD4 count is a good immunological marker of disease progression. Thus, a CD4 count of more than $25 \%$ shows that there is 
little immune suppression; 15-24\% moderate suppression and less than $15 \%$ severe suppression (World Health Organisation, 2005).

Prior to the introduction of antiretroviral therapy (ART) in 2004 in South Africa, respiratory tract infections were found in over $90 \%$ of HIV infected African children post mortem (Zwi et al, 2000). Respiratory tract infection accounted for $30-40 \%$ of paediatric inpatient admissions in HIV endemic regions with case fatality rates of between $15-28 \%$ (Zwi et al, 2000). Thus the high prevalence of respiratory conditions may have been partly attributable to many children not receiving highly active antiretroviral therapy (HAART) or having had an undiagnosed HIV infection.

A study by Cowburn et al (2004) completed in Cape Town raised an issue that health care workers cannot adopt a deontological approach or see treatment of those infected with HIV as an obligation due to "a high incidence of HIV infection and lack of access to HAART, coupled with resource constraints". Jeena (2005) discusses that in developing countries a much more utilitarian view has to apply until such time that resources to practise at optimum levels become available. Research with regard to HIV and respiratory care is scant and is thus required in order to develop data upon which policies can be built; and is required to guide policy, resource allocation and ethical decision making in South Africa. This study aims to determine the burden of disease with regard to the prevalence of respiratory conditions among paediatric patients infected with HIV/AIDS and to establish the need for chest physiotherapy.

\section{METHODS}

\section{Study setting and participants}

One hundred and twenty five children admitted to the paediatric wards at Steve Biko Academic Hospital (Pretoria) and Chris Hani Baragwanath Hospital (Johannesburg), Gauteng, South Africa were recruited for this study. Children included were those under the age of seven years diagnosed with a respiratory condition and infected with HIV/AIDS already confirmed by polymerase chain reaction (PCR) testing.

\section{Ethical Considerations}

Ethical approval was obtained from the Human Research Medical Ethics Committee at the University of the Witwatersrand and from the Faculty of Health Sciences Research Ethics Committee at the University of Pretoria. Consent was obtained from the parent or guardian and assent from the child where applicable, prior to data collection.

\section{Procedure}

Upon consent, patient files were used to complete a data collection form. The data collection form was completed two days post admission, five to seven days post admission and repeatedly five to seven days later until discharge and finally at discharge. Data collected included: age, gender, length of hospital stay, diagnosis of the respiratory conditions, the patients' CD4 count, viral load, ARV use, the combination of ARVs administered, length of drug use, patient history of ARV drug combination use, whether the mother was on ARVs, the necessity for physiotherapy intervention and the reason for physiotherapy intervention.

\section{Statistical analysis}

The data were reviewed and statistically analysed. The relationship between the respiratory categories and influencing factors was investigated using logistic or polytomous logistic regression. The relationship between length of stay and the influencing factors employed time to event analysis. Interpretation was performed at a 0.05 level of significance using.

\section{RESULTS}

The results of the study showed the average age of all the children under

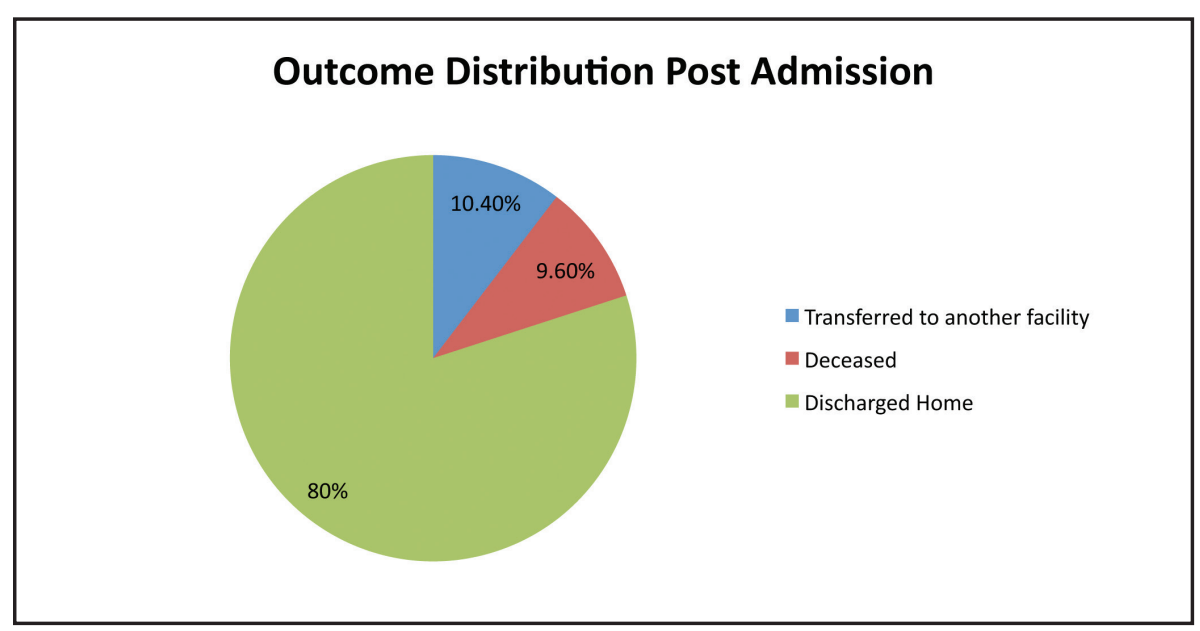

Figure 1: Outcome distribution post admission

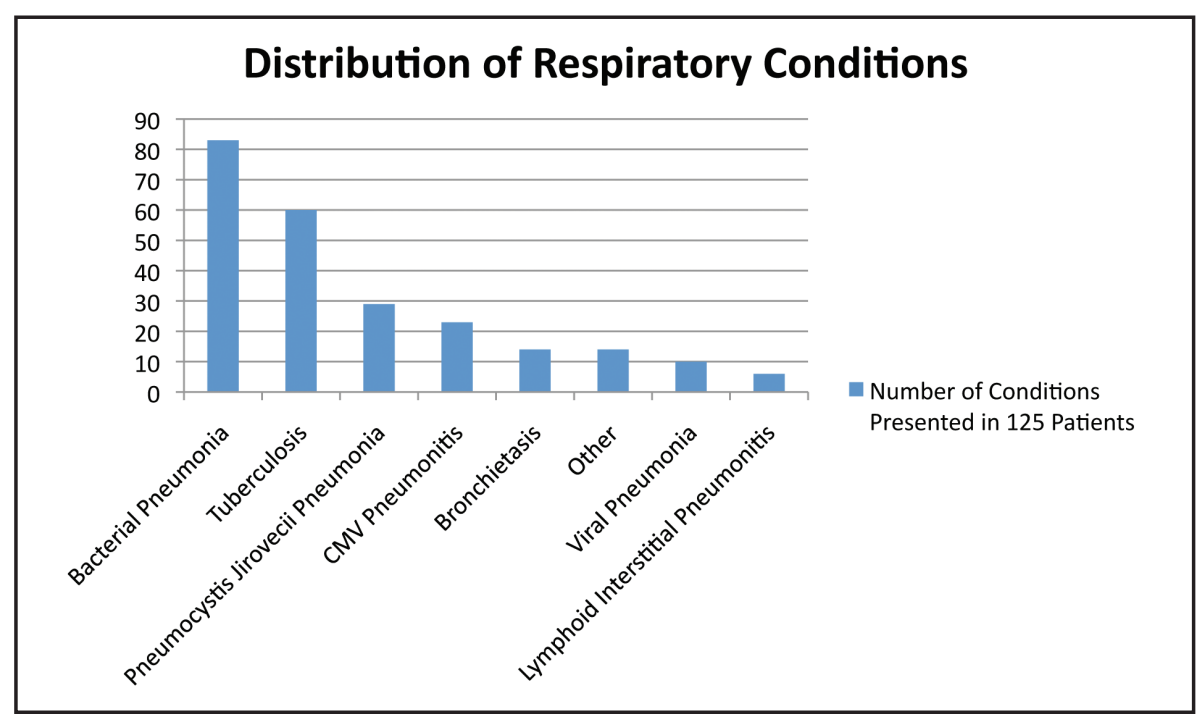

Figure 2: Distribution of respiratory conditions ( $n=239$ conditions) 
seven years (84 months) to be 21 months $( \pm \mathrm{SD}=23.64)$. Fifty-five percent of patients were boys. The average length of stay in hospital was 19 days $( \pm \mathrm{SD}=19.19)$.

The outcome of the sample $(n=125)$ after admission is presented in Figure 1.

The distribution of respiratory conditions was collated and categorised into eight groups. This is shown in Figure 2. 'Bacterial pneumonia' included all forms of bronchopneumonia, pneumonia, community and hospital acquired. 'Viral pneumonia' included bronchiolitis and all types of influenza. The 'Other' group included interstitial lung disease, emphyema, pleural effusion, laryngomalacia, bronchopulmo-

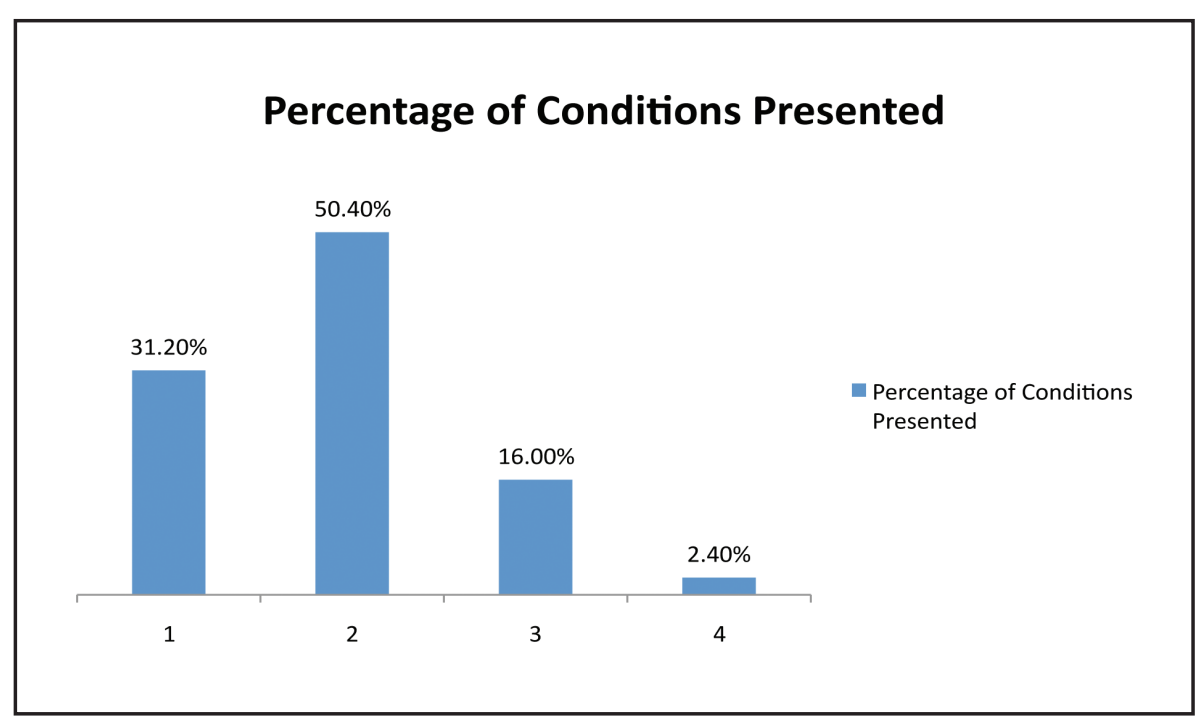

Figure 3: Distribution of the percentage of conditions presented

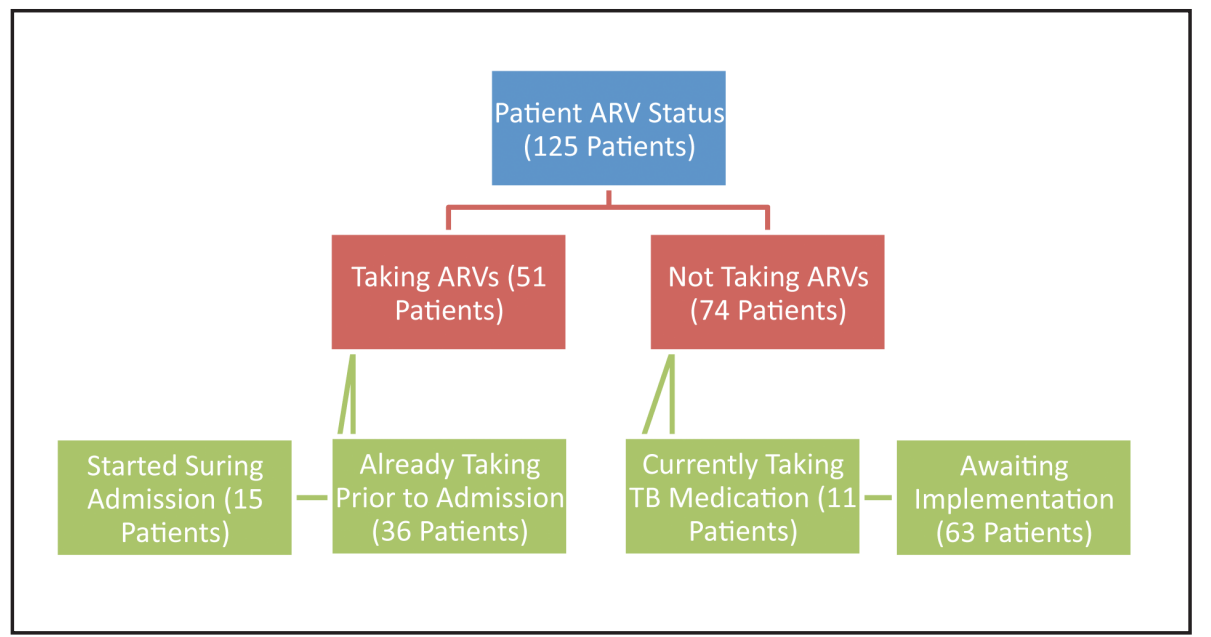

Figure 4: Breakdown of reasons for the status of ARV use

Table 1: Immunological status

\begin{tabular}{|l|c|c|c|c|}
\hline & Mean & SD & Median & IQR \\
\hline CD 4 Percentage & 17.33 & 10.96 & 16.7 & $8.94-21.3$ \\
\hline $\begin{array}{l}\text { CD 4 Absolute } \\
\text { (cell/mm })\end{array}$ & 631.36 & 610.36 & 417 & $233.5-811.5$ \\
\hline $\begin{array}{l}\text { Viral Load } \\
\text { (copies/mL) }\end{array}$ & 2664420 & 9080406 & 350000 & $\begin{array}{c}33000- \\
1550000\end{array}$ \\
\hline
\end{tabular}

* SD - standard deviation

** IQR - Inter-quartile range nary, dysplasia, mycobacterium avium complex (MAC), swine flu (H1N1) and lung fibrosis.

Patients presented with one to four respiratory conditions as depicted in Figure 3.

These were then categorised as a 'Low burden' (only one condition) or a 'High Burden' (more than one condition). Two thirds $(69 \%)$ of all the patients were classified as having a high burden of respiratory disease.

The number of children taking antiretroviral medication was 51 (41\%). Figure 4 demonstrates the breakdown of ARV use.

The average length of anti-retroviral use for the 36 patients that were already taking ARVs prior to admission was 10 months $( \pm \mathrm{SD}=11.61)$.

Of all the mothers there were only 31 (24.8\%) who were involved in a PMTCT programme.

Information regarding the immunity of the children is included in table 1.

The level of immune suppression was categorised into four stages (figure 5) according to the WHO staging, which accounts for age and CD4 percentage (for children under 5 years) or CD4 absolute count (for children 5 years and older).

The burden of respiratory disease was regarded as low or high burden as described above. The influencing factors include: anti-retroviral use, CD4 count, viral load, age and gender. A relationship was shown to exist with ARV use, CD4 count and gender (table 2).

In conclusion: there is a higher burden of disease among patients using anti-retrovirals, as the level of immunosuppression increases so does the burden of respiratory disease, and there is a higher burden of disease among female patients.

Using the Kaplan Meier survival curves there was a marginally significant difference $(p=0.06)$ between a low burden of disease and high burden with respect to mortality. The low burden group died earlier but had a shorter length of stay; the high burden group died later but had a longer length of stay. This relationship between burden of disease and the length of hospital stay was also statistically significant $(\mathrm{p}=0.029)$. 
Table 2: Summary of Findings

\begin{tabular}{|l|c|c|c|}
\hline & $\begin{array}{c}\text { Risk of increased } \\
\text { Burden }\end{array}$ & $\begin{array}{c}\text { Crudes odd } \\
\text { ratio }\end{array}$ & P value \\
\hline ARV non-users & $1 / 2$ & 0.54 & 0.13 \\
\hline $\begin{array}{l}\text { Mild } \\
\text { immunosuppression }\end{array}$ & $1^{1 / 2}$ & 1.66 & 0.50 \\
\hline $\begin{array}{l}\text { Advanced / Severe } \\
\text { immunosuppression }\end{array}$ & 2 & 2.01 & 0.20 \\
\hline Females & 2 & 2.23 & 0.05 \\
\hline
\end{tabular}

\section{Immune Suppression}

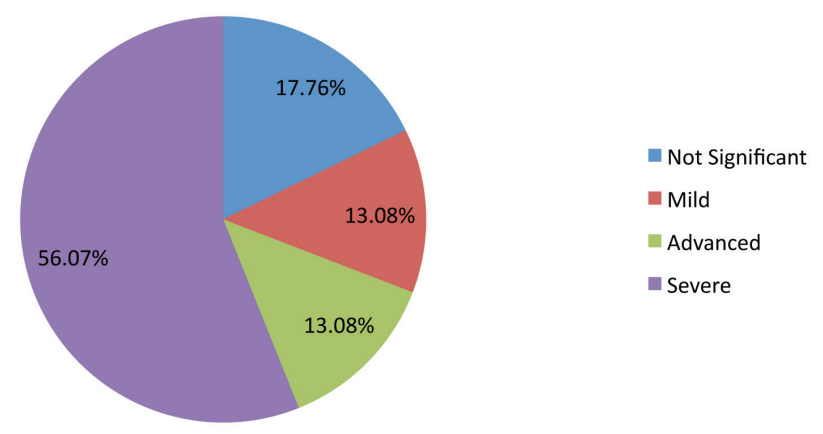

Figure 5: Level of immune suppression

\section{DISCUSSION}

Lower respiratory tract infections (LRTIs) are a major cause of morbidity and mortality in children aged less than five years in developing countries (Madhi et al, 2000; Zar and Mulholland, 2003). This study population consisted of 125 children all diagnosed with perinatally acquired HIV and respiratory illness with an average age of just under two years. The distribution of males to females was similar.

The length of hospital stay was approximately two and a half weeks with an $80 \%$ discharge rate. Madhi et al (2000) found in a South African based study that the average length of hospitalisation was less than seven days with mortality lower than $10 \%$. Further South African studies show mortalities of up to $16 \%$ (Ojikutu et al, 2008).

Of the twelve patients who died three were taking ARVs. These three had only started medication during the study; essentially making all children who died ARV naive, highlighting the problems arising as a result of late initiation of ARVs. Nine of the twelve children who died were under the age of six months. Pneumonia, PJP, CMV pneumonitis and TB were the diagnosed respiratory illnesses in these children, concurring with a 2004 Zambian study by Kouakoussui et al (2004).

Although Zar (2008) discusses a shift from acute to chronic exacerbations of respiratory disease, this state is not clearly depicted in this study due to the young population age. This study may offer more insight into acute respiratory diseases.

Pneumocystis jirovecii pneumonia occurred in $10 \%$ and $17 \%$ of children according to a study by Jeena (2005); however is represented by $23 \%$ of children in this study. Graham (2003) reports that PJP presents with severe pneumonia, usually in infants between two and seven months old. Of the twenty-nine children, 27 were seven months or younger. This demonstrates PJP's early presentation confirming the need or proper ante-natal HIV testing and PJP prophylaxis post-natally. Bacterial pneumonia was found in two thirds of all patients in this study. Current PJP prophylaxis has, however, lowered this infection rate by three times, making bacterial pneumonia a more common acute respiratory illness, as shown in this study and that conducted by Graham (2005). CMV pneumonitis, often associated with PJP (Graham, 2003) was found in $18.4 \%$ of children in this study.

Viral pneumonia (including bronchiolitis and influenza viruses) was not very common with only an eight percent presentation. This group remains important as repeated viral infections may result in chronic lung disease of which HIV infected children are susceptible (Zar, 2008).

This study found a low percentage of cases of LIP due to a number of reasons: the young study population, improved care of acute respiratory exacerbations, which in the long term may reduce the occurrence of chronic lung diseases and the under diagnosis of LIP as a result of high prevalence of TB, since the presenting features are very similar.

Half of the cases presented with tuberculosis. Tuberculosis remains a major disease in South Africa and its management of importance due to its co-infection with HIV resulting in more rapid deterioration of immune dysfunction, viral replication, and HIV progression; and more frequently other severe infections (Zar, 2008).

Bronchiectasis is a common presenting condition among children infected with HIV and occurs as a result of repeated lung tissue damage. It occurs in up to $16 \%$ of children (Rabie et al, 2007). Just over $11 \%$ of children in this study presented with bronchiectasis. Sheikh et al (1997) had similar results however the children had a mean age of seven and a half years.

The number of respiratory diseases presented in this study was classified as low burden when only one condition was present and a high burden when two or more conditions were present. This is clearly demonstrated with a $69 \%$ rate of high disease burden. 
A higher burden of disease among patients using ARVs was found. This result seems to be contradictory as the use of ARVs is known to improve immune status. Children receiving ARVs for a short and a long period of time were analysed in the same group, possibly masking the effect of ARVs in those who had been taking them for a longer time. It may also be that the children presenting with more conditions had been referred to the tertiary hospitals by secondary or primary institutions for more specialised care of complicated conditions, therefore the study only recruited children with a higher burden of disease, due to the tertiary institutions chosen.

The relationship between the level of immune suppression and the burden of disease showed that as the level of immunity decreased children were predisposed to infection. Children infected with HIV have a lower immunity and are thus more susceptible to infection and to having a number of co-existing conditions.

The results showed that girls are twice as likely to develop a higher burden of disease as boys. This contrasts findings by Kristensen and Olsen (2006) that girls tended to be better protected against acute respiratory infections than boys. Further study is needed to clarify this discrepancy.

This study sought to find whether a relationship between the burden of disease and the length of hospital stay and with respect to mortality exists. With regard to mortality the children with a low burden of disease died at earlier stages after hospital admission. The patients with a high burden of disease were admitted for longer and displayed incidents of mortality much later. Children admitted with only one condition such as pneumocystis jirovecii pneumonia, aggressive in its presentation, demised at an early stage of admission. The children identified to have a higher burden of disease may have had conditions less aggressive, may have received a more intense programme of care thus lengthening their hospital stay. No relationship between the age of the child and the point of hospital stay at which mortality occurred was found. Mortality was rather influenced by the number of conditions presented.

Of the sample only 36 were already taking ARVs, prior to admission, for an average length of 10 months $( \pm \mathrm{SD}=11.61)$. Sixty two patients were only diagnosed with HIV during hospital admission, and thus were still awaiting initiation of ARV treatment. The most commonly administrated drugs included: Stavudine, Lamivudine and Kaletra. In 2010, the National Department of Health in South Africa published "Guidelines for the Management of HIV in Children" suggesting that all diagnosed children under the age of one start ARVs immediately. Children between one and five years are eligible to start treatment if they are symptomatic (stage III or IV), have a CD4 count less than 750 cells $/ \mathrm{mm} 3$ or percentage CD4 count below $25 \%$. Children over five years of age may start ARV's when they too are symptomatic or have CD4 counts less than 350 cells/mm3. Studies show that early anti-retroviral treatment initiation lowers viral load and thus reduces the risk of opportunistic infections (Eley et al, 2006). The initiation of early ARV use has shown a $69-94 \%$ reduction in mortality and reduced early mortality rates within the first six months (Kitahata et al, 2009).

The proportion of current maternal anti-retroviral use was not evaluated; however it is an important factor influencing the burden of childhood disease. Maternal death is a major risk factor for poor survival in HIVexposed infants (Graham, 2005). Seven intervention trials from subSaharan Africa in largely breastfeeding populations demonstrated that the death of children by age one is approximately seven times greater when the mothers are HIV infected compared to noninfected (Newell et al, 2004).

One hundred and twenty of the total number of patients $(n=125)$ required physiotherapy mostly due to excess secretions and decreased air entry. The need for physiotherapy for each child was based upon the need to provide treatment due to excess secretions, decreased air entry, weak cough, poor exercise endurance, poor positioning or posture, poor breathing control or need for a home programme and caregiver education in the event of chronic lung diseases. Of the 120 patients the average need for physiotherapy was thirteen days. There are no studies, both nationally and internationally, that have been done before to investigate the length of time that physiotherapy is required.

\section{CONCLUSION}

This study aimed to determine the burden of disease with regard to the prevalence of respiratory conditions among paediatric patients infected with HIV/AIDS. The younger age group selected showed a predominance of acute respiratory disorders. Of the 125 children perinatally infected with $\mathrm{HIV}$, there was a mortality rate of just under $10 \%$ due to pneumonia, PJP, CMV pneumonitis and TB infection. Conditions observed were similar to previous studies, highlighting that PJP, bacterial and viral pneumonia, TB, LIP, CMV pneumonitis and bronchiectasis remain common conditions among children with HIV. This study substantiates a shift seen in increased bacterial pneumonia rather than PJP diagnoses, due to improved prophylactic measures.

The relationships between the burden of disease and its influencing factors showed that a higher burden of disease was related to the use of ARVs, a higher immuno-suppression, longer length of hospital stay, longer life span and in female patients. Despite six years of anti-retroviral therapy roll-out many children's HIV status remains undiagnosed leading to delayed initiation of $\mathrm{ARVs}$ and interim respiratory conditions. 


\section{REFERENCES}

Center for Disease Control and Prevention 1994. Revised Classification System for Human Immunodeficiency Virus Infection in Children Less Than 13 Years of Age. www.cdc.gov/mmwr (accessed 6 June 2009).

Cowburn C, Hatherill M, Eley B, Nuttall J, Hussey G, Reynolds L, Waggie Z, Vivian L, Argent A 2004. Short term mortality and implementation of antiretroviral treatment for critically ill HIVinfected children in a developing country. Archives of Disease in Children 92: 234-241.

Eley B, Davies M, Apolles P, Cowburn C, Buys H, Zampoli M, Finlayson H, King S, Nuttall J 2006. Antiretroviral treatment for children. South African Medical Journal September, Vol 96, No 9.

Graham S 2003. Impact of HIV on Childhood Respiratory Illness: Differences Between Developing and Developed Countries. Pediatric Pulmonology 36:462-468.

Graham S 2005. Non-tuberculosis opportunistic infections and other lung diseases in HIV-infected infants and children. International Journal of Tuberculosis Lung Disease 9:592-602.

Graham S 2007. HIV-related pulmonary disorders: practice issues. Annals of Tropical Paediatrics 27: 243-252.

Jeena P 2005. The role of HIV infection in acute respiratory infections among children in Sub-Saharan Africa. International Journal of Tuberculosis and Lung Disease 9: 708-715.

Kitahata M, Gange SJ, Abraham AG, Merriman B, Saag MS, Justice AC, Hogg RS, Deeks SG, Eron JJ, Brooks JT, Rourke SB, Gill J, Bosch RJ, Martin JN, Klein MB, Jacobson LP, Rodriguez B, Sterling TR, Kirk GD, Napravnik S, Rachalis AR, Calzavara LM, Horberg MA, Silverberg MJ, Gebo KA, Goedert JJ, Benson CA, Collier AC, Van Rompaey SE, Crane HM, McKaig RG, Lau B, Freeman AM, Moore RD for the NA-ACCORD Investigators 2009. Effect of Early versus Deferred Antiretroviral Therapy for HIV on Survival. The New England Journal of Medicine 360: 1815 1826.

Kouakoussui A, Fassinou P, Anaky M, Elenga N, Laguide R, Wemin M, Toure R, Menan H, Rouet F, Msellati P 2004. Respiratory manifestations in HIV-infected children pre- and post-HAART in Abidjan, the Ivory Coast. Paediatric Respiratory Reviews , 5: 311-315.
Kristensen I, Olsen J 2006. Determinants of acute respiratory infections in Soweto - a populationbased birth cohort. South African Medical Journal 96: 633-640.

Madhi S, Schoub B, Simmank K, Blackburn N, Klugman K 2000. Increased burden of respiratory viral associated severe lower respiratory tract infections in children infected with human immunodeficiency virus type 1 . Journal of Pediatrics, 78-84.

National Department of Health South Africa 2010. Guidelines for the Management of HIV in Children. 2nd Edition. www.hiv911.org.za/ wp-content/uploads/2010/04/2010-PaediatricGuidelines.pdf (accessed 19 July 2010).

Newell M, Coovadia H, Cortina-Borja M, Rollins N, Gaillard P, Dabis F 2004. Mortality of infected and uninfected infants born to HIV-infected mothers in Africa: a pooled analysis. Lancet, 123643.

Ojikutu B, Zheng H, Walensky R, Lu Z, Losina E, Giddy J, Freedberg K 2008. Predictors of mortality in patients initiating antiretroviral therapy in Durban, South Africa. South African Medical Journal 98: 204-208.

Parker M, Leveno D, Campbell T, Worrell J, Carozza S 1998. AIDS-Related Bronchogenic Carcinoma. Chest 113: 1.

Rabie H, Marais B, van Toorn R, Nourse P, Nel E, Goussard P, Sellers N, Cotton M 2007. Important HIV-associated conditions in HIV-infected infants and children. South African Family Practise 49: 19-23.

Sheikh S, Madiraju K, Steiner P, Rao M 1997. Bronchiectasis in Pediatric AIDS. Chest 112: 1202-07.

UNAIDS 2012. UNAIDS Report on the Global Aids Epidemic. http://data.unaids.org/pub/GlobalReport/2012/20121120_globalreport_en.pdf (accessed 27 March 2013).

World Health Organisation 2005. Interim who clinical staging of HIV/Aids and HIV/Aids case definitions for surveillance. www.who.int/hiv/pub/ guidelines /clinicalstaging.pdf. (accessed 201006-16).

Zar H 2008. Chronic Lung Disease in Human Immunodeficiency Virus (HIV) infected children. Pediatric Pulmonology 43: 1-10.
Zar H, Mulholland K 2003. Global Burden of Pediatric Respiratory Illness and the Implications for Management and Prevention. Pediatric Pulmonology 36:457-461.

Zwi K, Pettifor J, Soderlund N, Meyers T 2000. HIV infection and in-hospital mortality at an academic hospital in South Africa. Archives of Disease in Children 83: 227-230. 